\title{
Workplace-related smoking in New South Wales: extent of bans, public attitudes and relationships with relapse
}

\author{
Raoul A. Walsh, Christine L. Paul, Lorraine Paras, Fiona Stacey and Flora Tzelepis
}

\section{Introduction}

Second-hand smoke causes premature death and disease in children and adults who do not smoke. 'The desire to protect employees' health combined with concern about the legal risks to employers who allow smoking in the workplace ${ }^{2,3}$ has led to increasing levels of restriction on smoking in indoor workplaces. ${ }^{4,5}$ By 2005, 73\% of Victorian indoor workers were protected by total smoking bans and a further $23 \%$ by partial bans. ${ }^{6}$

No data are available on the extent of indoor workplace smoking bans in New South Wales (NSW). The NSW Smoke Free Environment Act 2000 prohibits smoking in 'enclosed public spaces' which covers a wide range of workplaces. There is, however, no actual ban on indoor workplace smoking in NSW, despite a complete ban in Australian workplaces being on the agenda of state and territory ministers in 2002.? Although major improvements have occurred, a lack of comprehensive workplace smoking bans put some staff and patrons of gaming and drinking establishments especially at risk of second-hand smoke exposure, as legal loopholes provide de facto exemptions to sections of entertainment venues in most Australian jurisdictions. ${ }^{8}$ The National Preventative Health Strategy has recommended legislation be tightened to protect against second-hand smoke exposure including in outdoor and indoor areas of such venues. ${ }^{9}$

From the early period of their introduction, smoking bans have enjoyed high levels of employee acceptability. ${ }^{10,11}$ Workplace bans
\end{abstract}

also reduce exposure to second-hand smoke whether measured via self-report ${ }^{12}$ or biochemically, ${ }^{13}$ as well as being associated with improvements in employee respiratory health. ${ }^{14,15}$

Workplace bans reduce short and long-term cigarette consumption, ${ }^{16,17}$ despite the influence of some delayed compensatory smoking. ${ }^{17}$ Although some studies have failed to find an increase in smoking cessation post-bans, this may be due to poor enforcement. ${ }^{18}$ Overall, the findings of three reviews indicate that workplace smoking bans are associated with declines in employee cigarette consumption and increased quitting. ${ }^{19-21}$

One of the consequences of workplace bans has been considerable 'exiled smoking',4,22,23 'Exiled smoking' refers to the practice of going outside the workplace for the purpose of smoking. In the 1990s, half of Victorian smokers reported engaging in 'exiled smoking' on their most recent work day. ${ }^{4}$ Smokers' reasons for leaving work to take a smoking break were not restricted to the "need to smoke" (44\%), but included "to get away from work" (43\%) and "to socialise" (14\%). Approximately half (51\%) of non-smokers (includes 'social smokers') had joined smokers outside their workplace, usually on an infrequent basis, and, of this group, 33\% had smoked outside at some time. ${ }^{24}$ Although non-smoking workers saw smokers as having a work benefit not available to them, most did not feel strongly deprived. ${ }^{24}$ Major qualifiers of these findings are that non-smokers in this study included 'social smokers' and that they were recruited by the smokers, and these factors may have generated a sample with

\section{Abstract}

Issue addressed: Little research has examined issues surrounding employee smoking outside smoke-free workplaces. The study's aims were to: 1) document the proportion of NSW indoor employees covered by total workplace smoking bans; 2) examine community perceptions of employee smoking during working hours; 3 ) identify the characteristics of having a supportive attitude toward tobacco control in the workplace; and 4) describe relationships between smoking relapse and workplace-related smoking.

Methods: Two cross-sectional, computer-assisted telephone interview surveys of randomly selected adults were conducted. Consent rates were $49.1 \%$ in 2004 and $45.8 \%$ in 2006, with sample sizes of 1,158 and 2,393 respectively.

Results: Total workplace bans were reported by $92.9 \%$ of indoor employees. Community attitudes to smoking in working hours were highly negative: $77.7 \%$ agreed smoking breaks waste too much time and $85.1 \%$ opposed smoking near workplace doorways. Being female, born in Australia and a non-smoker were associated with more negative attitudes. A higher proportion of smokers (78.3\%) perceived smoking was more common outside their place of work or study than at five other locations: rail/bus stop (60.2\%), friends' houses (59.3\%), own street (35.2\%), parks (34.3\%), and outside school (22.6\%). Of smokers making a quit attempt in the past year, $42.1 \%$ relapsed at home, $22.1 \%$ at licensed premises and $18.7 \%$ at work.

Conclusions: Findings emphasise the low support for smoking during or near work. Smoking outside workplaces is highly visible. Data on relapse suggest a modest relationship with workplace-related smoking.

Key words: smoking, tobacco, workplace smoking, second-hand smoke, relapse, surveys

Health Promotion Journal of Australia 2011; 22: 85-90

Employers and governments should capitalise on positive public opinion to ban smoking breaks and smoking near workplaces. 
less negative perceptions of exiled smoking. ${ }^{24} \mathrm{~A}$ qualitative study of 60 US nurses found that smokers were negatively perceived as spending less time with patients than non-smoker colleagues.2. An estimate of productivity losses due to off-site smoking breaks in a UK pharmaceutical company with totally smoke-free work-sites was 64 minutes per smoking employee per day. ${ }^{25}$

It is generally accepted that environmental stimuli associated with smoking almost certainly contribute to smoking relapse. ${ }^{26}$ Some evidence indicates workplace smoking restrictions are associated with lower rates of relapse in smokers who attempt to quit. ${ }^{27}$ The relationship of workplace-related smoking factors with relapse has, however, been little studied.

Thomson et a ${ }^{28}$ have recently argued the case for banning smoking in selected outdoor areas frequented by children in an effort to reduce modelling behaviour. In contrast, Chapman ${ }^{29}$ points to the paternalistic nature of some bans where, in his view, there is insufficient public health justification. The extension of workplace bans to include adjacent outside areas such as building entrances remains controversial. On the other hand, the view expressed by Borland et al ${ }^{4}$ that "leaving work to smoke should be treated like any unscheduled absences from duty, not given some privileged status" is likely to enjoy near universal endorsement by tobacco control workers. In the case of employee smokers, Chapman ${ }^{30}$ has recently argued that, for health and economic grounds, the time to end smoking breaks has clearly arrived. Although a case for avoiding stigmatising smokers has been well argued, ${ }^{31}$ the potential for discrimination against smokers in employment recruitment practices and in quality of health care provision have been the most serious ethical concerns raised. Currently proposed restrictions on workplace-related smoking can be viewed as promoting equity in employment conditions between smokers and non-smokers.

While there is clear evidence that the public, especially non-smokers, are generally supportive of smoking restrictions, ${ }^{32,33}$ little is known about general community views on workplace-related smoking issues such as 'exiled smoking'. Much of the research on workplacerelated smoking issues occurred in the 1990s and early 2000s when indoor bans were becoming well established in developed nations. Qualitative research ${ }^{23}$ and anecdotal reports ${ }^{34,35}$ suggest smoking outside public buildings remains a source of both annoyance and concern about toxic exposure, at least for some.

This research focused on a range of workplace-related smoking issues arising from the literature review. Given workplace smoking is not specifically banned in NSW ${ }^{8,9}$ an estimate of the prevalence of smoke-free indoor workplaces in NSW was obviously needed. Data on public attitudes to workplace smoking especially'exiled smoking' were required to inform policy making. Such attitudinal research was especially important to assess the community's position on approaches to employee smoking, an issue which could be viewed as potentially controversial. ${ }^{29,31}$ In addition, preliminary research among smokers which considered the potential role of workplacerelated smoking on relapse including the location of relapse, its social context and the source of the first cigarette as well as smokers' perception of the visibility of 'exiled smoking' was indicated.

The aims of this study were to: 1) document the proportion of NSW indoor employees working in organisations with total smoking bans; 2) examine community perceptions related to workplace smoking including the acceptability of employee smoking breaks and of smoking adjacent to workplaces; 3 ) identify the characteristics of having a supportive attitude toward tobacco control in the workplace; and 4) describe the relationship between smoking relapse and situational issues especially workplace-related factors, among employed people.

\section{Methods}

Data were derived from two cross-sectional, computer-assisted telephone interview surveys of randomly selected persons aged 18 years or older in households randomly selected from the NSW Electronic White Pages. Quotas in relation to age, gender and geographical area (metropolitan versus non-metropolitan) were applied and data were weighted to the NSW population. Although the two surveys contained a common core of questions, they also included some different sections. The surveys were conducted in October-December 2004 and October-December, 2006 using the same methodology which has been previously described. ${ }^{33}$

Eligibility rates were $59.5 \%$ (2004) and 54.4\% (2006). Consent rates were $49.1 \%$ (2004) and 45.8\% (2006). The full sample sizes were 3,503 (2004) and 4,770 (2006). The surveys included questions on a wide range of smoking issues; however, only material related to 'exiled smoking' and other aspects of workplace-related smoking will be reported here. The two surveys contained some workplace questions in common but others were only asked in one survey. In both surveys, randomly chosen sub-samples were asked the workplace-related questions: $n=1,158$ (2004) and $n=2,393$ (2006). Relapse-related items were answered by all current smokers in the full samples. Ethical approval was given by the University of Newcastle Human Research Ethics Committee.

\section{Analysis}

Responses of participants are reported using proportions and 95\% confidence intervals. In order to examine predictors of having a strong pro-tobacco control position on workplace-related smoking issues, responses to the six attitude items were examined. Each subject was allocated one point every time they endorsed the pro-tobacco control attitude on an item. Subjects scoring more than $83 \%$ (five or more out of six) were classified as having a strong pro-tobacco control position. The relationship between potential predictors and holding a strong position was assessed using chisquare analyses. Predictor variables that were statistically significant at the 0.20 level were entered into a backward logistic regression procedure. Odds ratios were calculated for variables that remained statistically significant at the 0.05 level in the final logistic regression. Goodness of fit was assessed using the Hosmer-Lemeshow test.

\section{Results}

On items that were common in the two surveys, no significant differences were found between 2004 and 2006 responses. In the case of repeat items, therefore, the more recent 2006 data are almost exclusively reported. 


\section{Workplace bans (2006 data)}

In 2006, 29.2\% reported not working at all, $2.6 \%$ said they worked outdoors and $0.3 \%$ did not know whether smoking was permitted at their work. This left 1,627 individuals who said they worked full-time, part-time or casually indoors. Of these, $92.9 \%$ (95\% Cl 91.6-94.1) said smoking was completely banned inside the building where they worked. Of current smokers ( $n=243$ ) who worked indoors, $86.3 \%$ (95\% Cl 82.6-91.1) reported a total ban which was less than the $93.9 \%$ (95\% Cl 92.7-95.2) of non-smokers ( $n=1384$ ) reporting smoking was banned inside their workplace. The proportion of respondents (2.8\%) who said they worked in a licensed hotel or club was too small for additional analyses. No other data were available on the occupational background of employed respondents.

\section{Attitudes to workplace smoking (2004 data)}

In 2004, all sub-sample respondents $(n=1,158)$ were asked their attitudes towards six workplace-related smoking items. The items focused heavily on the issue of 'exiled smoking' and agreement was indicated on a five-point scale from strongly agree to strongly disagree. Overall, attitudes towards workplace-related smoking were strongly negative. For example, 77.7\% (95\% Cl 75.2-80.1) strongly agreed/agreed that "smokers waste too much time because of their smoking breaks" and $85.1 \%$ (95\% Cl 83.1-87.2) strongly agreed/agreed that "smokers should not be allowed to smoke near workplace doorways". Table 1 details the proportions overall, and of current smokers and non-smokers adopting a pro-tobacco control position on each item (defined in the table footnote).

A pro-tobacco control in the workplace score was calculated using the six items. Each respondent was allocated one point for every item on which they adopted a pro-tobacco control position. Overall, the mean score was 4.5 (95\% Cl 4.4-4.6), however non-smokers $(n=986)$ had a significantly higher $(p<0.0001)$ mean of $4.7(95 \% \mathrm{Cl}$ 4.6-4.8) compared with the mean of 3.3 ( $95 \% \mathrm{Cl} 3.0-3.6)$ for current smokers ( $n=172)$

A backwards stepwise logistic regression analysis was conducted to examine factors associated with a high workplace pro-tobacco control score (5 or 6). Four variables: age, marital status, education and living with a smoker were not significantly associated with a high score. The odds ratio of having a high score was significantly increased for females 1.45 (95\% Cl 1.13-1.84), for people born in Australia $1.62(95 \% \mathrm{Cl} 1.22-2.16)$ and for non-smokers 4.37 (95\% Cl 3.06-6.24). The Hosmer-Lemeshow test $\left(\chi^{2}=3.59, \mathrm{df}=4, p=0.46\right)$ supports a reasonably well fitting model. Table 2 outlines the results of the logistic regression analysis.

\section{Smokers' perceptions of visibility of smoking at various sites (2006 data)}

In 2006, all current smokers ( $n=659$ ) were asked "how common is it to see someone smoking at each of the following places?" Six sites were listed including "outside your place of work or study." Some respondents who did not have the nominated site in their vicinity or who said they were unaware of what smoking occurred at a particular site were classified as 'not appropriate' or 'don't know' on that item and were excluded from the analysis for that site. This left three appropriate options:'common,'uncommon' and 'rare.' Table 3 details the sample size with a relevant response on each item and the percentage (95\% confidence intervals) who indicated smoking was commonly observed at that site.

The percentage of smokers who said smoking was common outside their place of work or study (78.3\%) was significantly higher than for any of the five other sites $(p<0.001)$.

\section{Factors related to relapse in employed smokers}

The 2004 and 2006 sub-samples included in this section were current smokers who reported being in any form of employment and had made an unsuccessful quit attempt in the past 12 months of two or more days duration. Respondents were asked about circumstances surrounding their relapse in the most recent quit attempt.

In the 2006 survey, smokers were not asked about who, if anyone, was smoking around them when they relapsed.

\section{Other people smoking at relapse (2004 data)}

Of this sub-sample ( $n=200), 70.5 \%(n=141)$ indicated that people around them were smoking when they first started smoking again.

Table 1: Attitudes towards workplace-related smoking (2004 data): percentages ( $95 \%$ confidence intervals) overall, and of smokers and non-smokers with pro-tobacco control position ${ }^{1}(n=1,158){ }^{2}$

Pro-tobacco control position \% $(95 \% \mathrm{Cl})$

\section{Statement}

\begin{tabular}{|c|c|c|c|}
\hline \multirow[t]{2}{*}{ Statement } & Non-smokers & Current smokers & Overall \\
\hline & $(n=986)$ & $(n=172)$ & $(n=1,158)$ \\
\hline a) Smokers should not be allowed to smoke near workplace doorways & $88.3(86.3-90.3)$ & $66.9(59.7-74.0)$ & $85.1(83.1-87.2)$ \\
\hline b) Smokers should be permitted smoking breaks in addition to their meal breaks & $86.5(84.4-88.7)$ & $74.1(67.5-80.7)$ & $84.7(82.6-86.8)$ \\
\hline c) Smokers waste too much time because of their smoking breaks ${ }^{3}$ & $82.7(80.3-85.1)$ & $48.5(40.9-56.1)$ & $77.7(75.2-80.1)$ \\
\hline $\begin{array}{l}\text { d) Smokers outside building entrances expose people moving past to passive } \\
\text { smoking }\end{array}$ & $80.8(78.3-83.3)$ & $57.9(50.5-65.3)$ & $77.4(74.9-79.8)$ \\
\hline e) Smoking outside workplaces gives those places a bad image & $77.0(74.4-79.7)$ & $47.9(40.4-55.5)$ & $72.7(70.1-75.3)$ \\
\hline f) Smoking should be permitted during work time for outdoor workers & $59.8(56.7-62.9)$ & $40.4(33.0-47.7)$ & $56.9(54.0-59.7)$ \\
\hline
\end{tabular}

1. Pro-tobacco control position was strongly agree/agree on items a), c) d) and e), and disagree/strongly disagree on items b) andf).

2. $n$ sizes vary on items due to missing data.

3. Item c) was repeated in 2006: non-smokers 81.1 (79.4-82.8), current smokers 48.3 (42.9-52.7) and overall 76.4 (74.7-78.1). 
The most common backgrounds of these other smokers were: friend or acquaintances $67.4 \%$ (95\% Cl 59.5-75.2); spouse or family members 27.7\% (95\% Cl 20.2-35.1); and work colleagues 23.4\% (95\% Cl 16.3-30.5).

\section{Location of relapse (2006 data)}

Subjects ( $n=235$ ) were asked where they were when they first started smoking again. The four most commonly nominated locations were: home 42.1\% (95\% Cl 35.8-48.5); licensed premises 22.1\% (95\% Cl 16.8-27.5); work 18.7\% (95\% Cl 13.7-23.7); and party/someone else's home/outdoor venue $8.1 \%$ (95\% Cl 4.6-11.6).

\section{Source of first cigarette (2006 data)}

Subjects ( $n=235$ ) were asked how they obtained the first cigarette when they started to smoke again. Six main sources were identified with workmate being least common: friend 40.9\% (95\% Cl 34.5-47.2); impulse cigarette purchase $16.6 \%$ (95\% Cl 11.8-21.4); family member 13.2\% (95\% Cl 8.8-17.5); considered cigarette purchase 10.2\% (95\% Cl 6.3-14.1); cigarettes still kept 9.4\% (95\% Cl 5.6-13.1); and workmate $6.4 \%(95 \% \mathrm{Cl} 3.2-9.5)$

\section{Discussion}

The vast majority (93\%) of NSW indoor workers report that smoking is completely banned inside their workplace. The level of total bans is higher than that reported in a 2005 Victorian survey (73\%). ${ }^{6}$
Although a high proportion of NSW employees do work in smokefree conditions, there is still room for improvement. It is not known whether the lower level of total smoking bans reported by current smokers (86\%) compared with non-smokers (94\%) in this study reflects that smokers are more likely to work where there is no smoking ban or that some smokers do not comply with total bans or that smokers are unaware of such bans.

Community attitudes to workplace-related smoking especially to issues surrounding 'exiled smoking' are very negative. A 1990s survey of mainly blue-collar indoor workplaces in Victoria and South Australia with smoking bans documented that 39\% of smokers reported leaving work to smoke one or more times per day during non-break periods. ${ }^{36}$ The high perceived visibility of smoking outside work by smokers in this study tends to support anecdotal evidence that this also remains a common practice in NSW.

A substantial majority surveyed identified'exiled smoking'as posing passive exposure, productivity and company image problems, and endorsed the view that smoking should not be permitted near workplace doorways and were opposed to special smoking breaks. This is in line with recommendations of the National Preventative Health Strategy calling for legislation to eliminate smoking near the entrances to buildings and air-conditioning intake points. ${ }^{9}$ The only attitude item on which opinion was relatively evenly divided related to smoking by outdoor workers during work time.

\begin{tabular}{|c|c|c|c|c|c|}
\hline Variable & n size & $\begin{array}{c}\text { Parameter } \\
\text { estimate }\end{array}$ & SE & $\begin{array}{c}\text { Odds ratio } \\
(95 \% \mathrm{Cl})\end{array}$ & $p$ \\
\hline Constant & & -1.46 & 0.22 & & \\
\hline \multicolumn{6}{|l|}{ Gender } \\
\hline male $^{2}$ & 570 & & & & \\
\hline female & 588 & 0.37 & 0.12 & $1.44(1.13-1.84)$ & 0.003 \\
\hline \multicolumn{6}{|l|}{ Born in Australia } \\
\hline $\mathrm{no}^{2}$ & 263 & & & & \\
\hline yes & 895 & 0.48 & 0.15 & $1.62(1.22-2.16)$ & 0.009 \\
\hline \multicolumn{6}{|l|}{ Smoking status } \\
\hline current smoker $^{2}$ & 172 & & & & \\
\hline non-smoker & 986 & 1.47 & 0.18 & $4.37(3.06-6.2)$ & $<0.0001$ \\
\hline
\end{tabular}

1. Four variables: age, marital status, education and living with a smoker did not have significant effects

2. Reference group

Table 3: Smokers' perceptions of how visible smoking is at various locations (2006 data): sample size of subjects providing a relevant response for each location, and the percentage ( $95 \%$ confidence intervals) indicating smoking was common at that site.

\begin{tabular}{|c|c|c|}
\hline Location & Sample size & $\begin{array}{l}\text { Proportion perceiving smoking to be common at } \\
\text { specified location } \\
\%(95 \% \mathrm{Cl} \text { 's) }\end{array}$ \\
\hline a) Outside place of work or study & 540 & $78.3(74.9-81.8)$ \\
\hline b) Local bus stop or railway station & 480 & $60.2(55.8-64.6)$ \\
\hline c) Houses of friends who live locally & 636 & $59.3(55.5-63.1)$ \\
\hline d) In own street & 620 & $35.2(31.4-38.9)$ \\
\hline e) Local park, oval or playground & 554 & 34.3.(30.3-38.2) \\
\hline f) Outside local school & 456 & $22.6(18.7-26.4)$ \\
\hline
\end{tabular}


Given the documented public support and the health and economic arguments, 25,30 the rationale for new policies restricting workplacerelated smoking seems strong. In the face of concerns about stigmatising smokers, ${ }^{31}$ it should be stressed that new policies in this area do not involve discriminatory policies against smokers. In fact, there is a strong equity argument, especially in relation to the elimination of smoking breaks, which was supported by approximately three-quarters of current smokers in this study. Bayer ${ }^{37}$ has pointed out that some arguments against the denormalisation of smoking are based on assumptions not evidence. Nonetheless, to ameliorate any potential stigmatisation, policies should stress that unacceptable smoking behaviours are the focus, not smokers themselves. For example, smokers would still be able to smoke in normal meal breaks away from the workplace. In addition, adequate notice could be given prior to policy introduction and, during this time, the availability of voluntary smoking cessation programs, ideally in the employers' time, could be promoted. It is also important that policy makers ensure that any further moves to restrict smoking in other areas do not lead to discrimination against smokers in the future.

In relation to the characteristics of those having a high pro-tobacco control score, it is unsurprising that non-smoking was the strongest predictor. Less predictable was the finding that being born in Australia and being female were also related to having a higher score. Perhaps one legacy of the relatively long history of tobacco control in Australia is that Australian-born persons are more likely to be supportive of many measures to discourage smoking. Nonetheless, country of birth did not emerge as a predictor in a related study examining a broader array of tobacco control measures. ${ }^{33}$ An alternative explanation may be that those born outside Australia in this survey were more involved in lower social status occupations where smoking is less marginalised.

A recent laboratory study found that both exposure to cigarette cues and increasing availability of those cues produced higher levels of craving to smoke. ${ }^{38}$ In the study reported here, $78 \%$ of current smokers identified smoking as being common outside their workplace, significantly more than for any of the other five sites assessed. It is likely that constantly seeing and smelling work colleagues smoking outside work would both reinforce smoking, and contribute to relapse in smokers attempting to quit, especially those with prolonged cravings. In this context, it is worth emphasising that, although the influence of family and friends appeared to be more strongly related to relapse in the employed smokers who had made a quit attempt in the past year, nearly a quarter of these unsuccessful quitters (24\%) reported work colleagues were smoking around them when they started smoking again and almost a fifth (19\%) of relapses occurred at work. Workmates, however, were not a common source (6\%) for relapsers' first cigarette. Although these data indicate there may be a modest relationship between workplace-related smoking and relapse, they do not establish a cause-effect association. In this context, it should be noted that full-time employees spend approximately one-third of their waking time at work (assuming 35-hour working week, eight hours sleep per day). Taking this proportion into account, indoor workplaces may represent a comparitively safer haven from smoking relapse.
Nonetheless, while relapse at work may not be relatively common, measures discussed earlier, which could reduce this problem in an equitable way should be introduced.

The main limitation of this study was the modest consent rates of the two surveys which, however, were similar to those of other Australian smoking surveys. ${ }^{39,40}$ The use of quotas to increase representativeness of subjects helped reduce this problem. Social desirability phenomena may have influenced some subject responses. Knowing the survey was being conducted by the NSW Cancer Council may have encouraged some subjects to adopt a more negative position about workplace-related smoking. The very small and non-significant differences in subject response patterns on items that were repeated in the two surveys (2004 data not reported on repeat items) show the consistency of the reported proportions. This study was also unable to identify the cause of apparent differences between smokers' and non-smokers' reports about the prevalence of workplace smoking restrictions. Recent qualitative work indicates that low socio-economic work environments are perceived as more conducive to smoking with less anti-smoking pressures and more access to smoking breaks. ${ }^{41}$ The lack of survey data on respondent occupation (apart from licensed premises employment) precluded investigation of this issue.

These data were collected in smoking omnibus surveys where the workplace-related questions represented a minority of the questions asked. Future research could explore in more detail the situations 'at work' where relapse occurred for example, on or off the worksite, indoors or outdoors, during an authorised or an unofficial break, and while travelling to, from or during work. Smokers' perceptions of whether relapse was related to workplace stress, the sight of work colleagues smoking or to other workplace-related factors could also be investigated. Qualitative research could complement survey methods in this endeavour.

\section{Conclusion}

Indoor workplace smoking bans have achieved high coverage in NSW. Nonetheless, some workers, especially in the hospitality area, remain unprotected and legislation is required to ensure a complete ban without loopholes. The potential of 'exiled smoking' to undermine some of the health effects of workplace smoking bans was identified over a decade ago. ${ }^{4}$ This study indicates there would be strong public support, based on environmental tobacco smoke protection and productivity concerns, for measures to curb indoor employees from going outside to smoke during formal work time, and to reduce smoking adjacent to workplaces. Company policies and/or government legislation, such as recommended in the National Preventative Health Strategy, ${ }^{9}$ to restrict smoking near workplace entrances could build on this solid platform of support. In this context, the recent decision by the Commonwealth Department of Health and Ageing to ban employees from smoking during work hours, "when representing the department in any capacity" or within 15 metres of the workplace, could set an example for other organisations to follow. ${ }^{42} \mathrm{~A}$ reduction in 'exiled smoking' and in all smoking adjacent to offices and other work buildings may also have potential to reduce smoking cravings and relapse, among smokers who wish to quit. 


\section{Acknowledgements}

This project was undertaken by the Centre for Health Research \& Psycho-oncology (CHeRP). CHeRP was funded by the Cancer Council NSW, The University of Newcastle, and received infrastructure support from the Hunter Medical Research Institute and the University of Newcastle Priority Research Centre for Health Behaviour. Christophe Lecathelinais provided extensive statistical assistance. Thanks to all the community members who were involved in these surveys. The views expressed are not necessarily those of the Cancer Council NSW.

\section{References}

1. Office of the Surgeon General. The Health Consequences of Involuntary Exposure to Tobacco Smoke: A Report of the Surgeon General - Executive Summary. Washington (DC): U.S. Department of Health and Human Services; 2006.

2. Palin M, Young M. The impact of smoking litigation on Australian workplaces. Tob Control. 1994;3:78-9.

3. Zellers L, Thomas MA, Ashe M. Legal risks to employers who allow smoking in the workplace. Am J Public Health. 2007;97:1376-82

4. Borland R, Morand M, Mullins R. Prevalence of workplace smoking bans in Victoria. Aust NZJ Public Health. 1997;21:694-8.

5. Tynan M, Babb S, MacNeill A. State smoking restrictions for private-sector worksites, restaurants and bars - United States, 2004 and 2007. MMWR Morb Mortal Wkly Rep. 2008;57:549-52.

6. Germain D. Smoking Bans in Victorian Workplaces: 2005 Update. Melbourne (AUST): Centre for Behavioural Research in Cancer, The Cancer Council Victoria, 2007. CBRC Research Paper Series No.: 24

7. ABC News Online. National Workplace Smoking Ban on Agenda at State Meeting [Internet]. Sydney (AUST): Australian Broadcasting Commission; 2002 November 8 [cited 2009 Dec 4]. Available from: http://www.abc.net.au/news/politics/2002/11/ item20021108100825_1.htm

8. Sanders S. Call to End Tobacco Smoke's Defacto OHS Exemption. Sydney (AUST): Smoke-free Australia coalition for clean safe workplaces, ASH Australia; 2009 August 27 [cited 2009 Dec 4]. Available from: http://www.ashaust.org.au/SF'03/ releases/090827.htm

9. National Preventative Health Taskforce. Australia: The Healthiest Country by 2020 National Preventative Health Strategy - The Roadmap for Action. Canberra (AUST): Commonwealth of Australia; 2009, Publications Number P3-5444.

10. Borland R, Owen N, Hill D, Chapman S. Staff members'acceptance of the introduction of workplace smoking bans in the Australian public service. Med J Aust. 1989;151:525-8.

11. Hocking B, Borland R, Owen N, Kemp G. A total ban on workplace smoking is acceptable and effective. J Occup Environ Med. 1991;33:163-7.

12. Skeer $M$, Cheng D M, Rigotti N A, Siegel M. Secondhand smoke exposure in the workplace. Am J Prev Med. 2005;28:331-7.

13. Bondy SJ, Zhang B, Kreiger N, Selby P, Benowitz N, Travis $H$, et al. Impact of an indoor ban on bar workers' exposure to secondhand smoke. J Occup Environ Med. 2009:51:612-19.

14. Eisner MD, Smith AK, Blanc PD. Bartenders' respiratory health after establishment of smoke-free bars and taverns. JAMA. 1998;280:1909-14.

15. Ayres JG, Semple S, MacCalman L, Dempsey S, Hilton S, Hurley HF, et al. Bar workers' health and environmental tobacco smoke exposure (BHETSE): symptomatic improvement in bar staff following smoke-free legislation in Scotland. Occup Environ Med. 2009:66:339-46.

16. Borland R, Champan S, Owen N, Hill D. Effects of workplace smoking bans on cigarette consumption. Am J Public Health. 1990;80:178-80.

17. Owen N, Borland R. Delayed compensatory cigarette consumption after a workplace smoking ban. Tob Control. 1997;6:131-5.

18. Biener L, Nyman A L. Effect of workplace smoking policies on smoking cessation: results of a longitudinal study. J Occup Environ Med. 1999;41:1121-7.

19. Farrelly MC, Evans WN, Sfekas AE. The impact of workplace smoking bans: results from a national survey. Tob Control. 1999;8:272-7.

20. Brownson RC, Hopkins DP, Wakefield MA. Effects of smoking restrictions in the workplace. Annu Rev Public Health. 2002;23:333-48.

21. Fichtenberg CM, Glantz SA. Effect of smoke-free workplaces on smoking behaviour: systematic review. BMJ. 2002;325:188-95.

22. Sarna L, Bialous SA, Wewers ME, Froelicher E S, Danao L. Nurses, smoking and the workplace. Res Nurs Health. 2005;28:79-90.

23. Parry O, Platt $\mathrm{S}$, Thompson C. Out of sight, out of mind: workplace smoking bans and the relocation of smoking at work. Health Promot Int. 2000;15:125-33.

24. Clarke J, Borland R, McGartland M. The effects of smoking outside workplaces on non-regular smokers. J Occup Med. 1997;39:734-9.

25. Ryan PJ, Crampia K. Time cost associated with smoking at work highlighted by baseline survey of employees participating in a workplace smoking cessation programme. J Occup Med. 2006;56:510.
26. Perkins KA. Cues must increase smoking behaviour to be clinically relevant. Addiction. 2009;104:1620-2.

27. Farkas AJ, Gilpin EA, Distefan JM, Pierce JP. The effects of household and workplace smoking restrictions on quitting behaviours. Tob Control. 1999;8:261-5.

28. Thomson G, Wilson N, Edwards R. Children tend to copy what they observe and are influenced by the normality of smoking around them. BMJ. 2008;337:a2806.

29. Chapman S. Zero tolerance of tobacco smoke in outdoor public settings is nakedly paternalistic. BMJ. 2008;337:a2804.

30. Chapman S. Time to end smoking break exceptionalism [Internet]. Sydney Morning Herald. 2010 January 12 [cited 2010 Apr 14]. Available from: http://www.smh.com. au/opinions/society-and-culture/time-to-end-smoking-break-exceptionalism20100112-m3kf.html

31. Bell K, Salmon A, Bowers M, Bell J, McCullough L. Smoking, stigma and tobacco 'denormalization': Further reflections on the use of stigma as a public health tool. A commentary on Social Science \& Medicine's Stigma, Prejudice, Discrimination and Health Special Issue (67:3) Soc Sci Med. 2010;70:795-9.

32. Poland BD, Cohen JE, Ashley MJ, Adlaf E, Ferrence R, Pederson LL, et al. Heterogeneity among smokers and non-smokers in attitudes and behaviour regarding smoking and smoking restrictions. Tob Control. 2000;9:364-71.

33. Walsh RA, Paul CL, Tzelepis F, Stojanovski E, Tang A. Is government action out-of-step with public opinion on tobacco control?: results of a New South Wales population survey. Aust NZ J Public Health. 2008;32:482-8.

34. Edgar B. Tobacco addicts don't come close to paying their way [Internet]. Sydney Morning Herald. 2009 July 8 [cited 2009 Jul 10]. Available from: http://www.smh. com.au/opinion/letters/tobacco-addicts-dont-come-close-to-paying-their-way20090707-dbr9.htm

35. AAP. Sydney council bans alfresco smoking [Internet]. Sydney Morning Herald. 2010 March 24 [cited 2010 Apr 8]. Available from: http://news.smh.com.au/breakingnews-national/sydney-council-bans-alfresco-smoking-20100324-qvew.html

36. Borland R, Cappiello M, Owen N. Leaving work to smoke. Addiction. 1997;92:1361-8.

37. Bayer R. Stigma and the ethics of public health redux: A response to Bell et al. Soc SciMed. 2010;70:800-1.

38. Bailey SR, Goedeker KC, Tiffany ST. The impact of cigarette deprivation and cigarette availability on cue-reactivity in smokers. Addiction. 2010;105:364-72.

39. Hill DJ, White VM, Scollo M. Smoking behaviours of Australian adults in 1995: trends and concerns. Med J Aust. 1998:168:209-13.

40. Australian Institute of Health and Welfare. 2004 National Drug Strategy Household Survey: First Results. Drug Statistics Series No.: 13. Canberra (AUST): AlHW; 2005. AlHW Catalogue No.: PHE57.

41. Paul CL, Ross S, Bryant J, Hill W, Bonevski B, Keevy N. The Social Context of Smoking: A Qualitative Study Comparing Smokers of High Versus Low Socioeconomic Position. BMC Public Health. 2010,10:211

42. Wallace N. Health Department bans staff smoke breaks [Internet]. Sydney Morning Herald. 2010 January 13 [cited 2010 Jan 20]. Available from: http://www.smh.com. $\mathrm{au} /$ national/health-department-bans-staff-smoke-breaks-20100111.m2si.html

\section{Authors}

Raoul A Walsh, Centre for Health Research \& Psycho-oncology, The Cancer Council New South Wales/University of Newcastle and Hunter Medical Research Institute.

Christine L Paul, Health Behaviour Research Group, Priority Research Centre for Health Behaviour, University of Newcastle and Hunter Medical Research Institute.

Lorraine Paras and Fiona Stacey, Centre for Health Research \& Psychooncology, The Cancer Council New South Wales/University of Newcastle and Hunter Medical Research Institute.

Flora Tzelepis, Health Behaviour Research Group, Priority Research Centre for Health Behaviour, University of Newcastle and Hunter Medical Research Institute.

\section{Correspondence}

Conjoint Associate Professor Raoul Walsh, Centre for Health Research \& Psycho-oncology, University of Newcastle, Room 230A, Level 2 David Maddison Building, Callaghan, NSW 2308; e-mail:Raoul.Walsh@newcastle.edu.au 